\title{
Benign Adrenal Gland Pheochromocytoma
}

National Cancer Institute

\section{Source}

National Cancer Institute. Benign Adrenal Gland Pheochromocytoma. NCI Thesaurus.

Code C48305.

A sporadic or familial pheochromocytoma that is confined to the adrenal gland and does not have any metastatic potential. The majority of cases are sporadic, and usually unilateral. Familial cases are usually bilateral. 